\title{
Inflammatory Bowel Disease Patients' Perspectives during COVID-19 Pandemic: Results from a Portuguese Survey
}

\author{
Joana Branco Revés ${ }^{\mathrm{a}}$ Catarina Frias-Gomes ${ }^{\mathrm{a}}$ Bárbara Morão ${ }^{\mathrm{a}}$ \\ Catarina Nascimento ${ }^{a}$ Carolina Palmela $^{\text {a Catarina Fidalgo }}{ }^{a}$ \\ Lídia Roque Ramos $^{a}$ Ana Sampaio $^{\mathrm{b}}$ Luísa Glória ${ }^{\mathrm{a}}$ Marília Cravo ${ }^{\mathrm{a}, \mathrm{c}}$ \\ Joana Torres ${ }^{\mathrm{a}, \mathrm{c}}$ \\ ${ }^{a}$ Gastroenterology Division, Surgical Department, Hospital Beatriz Ângelo, Loures, Portugal; b Associação \\ Portuguesa da Doença Inflamatória do Intestino (APDI), Matosinhos, Portugal; ' ${ }^{F}$ aculdade de Medicina, \\ Universidade de Lisboa, Lisbon, Portugal
}

\section{Keywords}

Inflammatory bowel disease $\cdot$ Crohn's disease $\cdot$ Ulcerative colitis · COVID-19

\section{Abstract}

Introduction: Patients with inflammatory bowel disease (IBD) do not seem to be at increased risk of infection by SARSCoV-2, but there is a concern whether immunosuppressive therapy may be associated with more severe disease. Several clinical practice recommendations have been published to help guide IBD care during the COVID-19 pandemic. Nonetheless, few studies have addressed patients' perspectives and fears. We aimed to evaluate Portuguese IBD patients' perspectives on the clinical management of their disease during the SARS-CoV-2 pandemic as well as the impact on their professional life. Methods: An anonymous electronic survey was created using REDCap and was distributed by the Portuguese Association of Inflammatory Bowel Disease (APDI) between May and August 2020. Patients' perspectives on immunosuppressive therapy, disease management, interaction with gastroenterology departments, and the impact of the pandemic in their professional life were assessed. Patients' proposals to improve medical care were also evalu- ated. Descriptive analysis and logistic regression were performed. Results: A total of 137 participants answered the survey (79.6\% females, mean age $41.7 \pm 12.1$ years). Although having IBD and receiving treatment with immunosuppressors (thiopurines, steroids, or biologics) were considered promotors of anxiety, most patients (85.4\%) agreed that disease remission was a priority and only a minority of patients interrupted their treatment during the pandemic. In multivariate analysis, active disease, biologic treatment, and use of corticosteroids in the last 3 months were perceived by the patients as high-risk features for increased risk of SARSCov-2 infection and more severe disease. Fifty-nine patients (44\%) believed that their follow-up was influenced by the pandemic and only $58.8 \%$ felt that they had the opportunity to discuss their therapeutic options with their doctor. Sixtythree patients $(46.0 \%)$ were working from home during the pandemic, although this decision was related to IBD and immunosuppressive therapy in only 36.5 and $39.7 \%$ of the cases, respectively. Areas where care could have been improved during the pandemic were identified by patients, namely enhancement of the communication with IBD professionals,

J.B.R. and C.F.-G. share co-first authorship. karger@karger.com www.karger.com/pjg

Karger $\stackrel{\text { ' }}{5}$ BOPEN ACCESS (c) 2021 Sociedade Portuguesa de Gastrenterologia. Published by S. Karger AG, Basel

This is an Open Access article licensed under the Creative Commons Attribution-NonCommercial-4.0 International License (CC BY-NC) (http://www.karger.com/Services/OpenAccessLicense), applicable to the online version of the article only. Usage and distribution for commercial purposes requires written permission.
Correspondence to:

Joana Torres, joanatorres00@ gmail.com 
conciliation of telemedicine with face-to-face appointments, and facilitation of the interaction between patients and employers. Conclusion: Most patients agreed that maintaining IBD remission is crucial, and only a minority of the patients stopped their treatment as per their own initiative. IBD status only had a small influence on patients' professional activity during the COVID-19 outbreak, with most changes being related to the pandemic itself.

(C) 2021 Sociedade Portuguesa de Gastrenterologia Published by S. Karger AG, Basel

\section{Perspetivas dos doentes com doença inflamatória do intestino durante a pandemia COVID-19: resultados de um inquérito português}

\section{Palavras Chave}

Doença inflamatória do intestino - Doença de Crohn . Colite ulcerosa $\cdot$ COVID-19

\section{Resumo}

Introdução: Os doentes com doença inflamatória do intestino (DII) não parecem ter um risco aumentado de infeção por SARS-CoV-2, mas existe receio de que a terapêutica imunossupressora possa estar associada a doença mais grave. Durante a pandemia COVID-19 foram publicadas recomendações clínicas para ajudar no seu tratamento, mas poucos estudos avaliaram as perspetivas e receios dos doentes. O presente estudo tem como objetivo avaliar as perspetivas dos doentes portugueses com DII relativamente à gestão da sua doença durante a pandemia e enfatizar a influência da COVID-19 na sua vida laboral. Métodos: Um inquérito anónimo eletrónico foi desenvolvido através do REDCap e divulgado pela Associação Portuguesa da Doença Inflamatória do Intestino (APDI) entre maio e agosto de 2020. Foram analisados dados relativos às perspetivas dos doentes sobre a terapêutica imunossupressora, gestão da doença, interação com os serviços de gastrenterologia e impacto da pandemia na vida laboral. As propostas dos doentes para melhorar a qualidade dos cuidados de saúde também foram avaliadas. Foi realizada uma análise estatística descritiva e regressão logística para avaliar fatores preditores. Resultados: Um total de 137 doentes responderam ao inquérito $(79.6 \%$ do sexo feminino, com idade média de $41.7 \pm 12.1$ anos). Apesar de a DII e imunossupressão serem considerados fatores promotores de ansiedade, a maioria dos doentes (85.4\%) concordou que a manutenção da remissão da doença é uma prioridade e apenas seis doentes interromperam a terapêutica durante a pandemia. Na análise multivariada, a presença de doença ativa, terapêutica com biológico e uso de corticoides nos últimos três meses foram considerados pelos doentes fatores preditores para um maior risco de infeção e maior gravidade da doença. Cinquenta e nove doentes (44\%) consideraram que o seu seguimento clínico foi influenciado pela pandemia e apenas 58.8\% considerou que teve a oportunidade de discutir as opções terapêuticas com o seu médico. Sessenta e três doentes (46\%) estiveram em teletrabalho durante a pandemia, apesar de esta decisão ter estado relacionada com a DII e com a imunossupressão em apenas $36.5 \%$ e $39.7 \%$ dos casos, respetivamente. Foram identificadas áreas onde os cuidados prestados podem ser melhorados, incluindo, melhoria da comunicação com os especialistas de DII, conciliação da telemedicina com a medicina presencial e facilitação da interação entre doentes e empregadores. Conclusão: A maioria dos doentes concordou que a manutenção da remissão clínica é essencial e apenas uma minoria suspendeu a medicação por iniciativa própria. $\mathrm{O}$ estado da doença apenas teve uma pequena influência nas alterações laborais dos doentes com DII, tendo a maioria das decisões ocorrido como consequência direta da pandemia.

(c) 2021 Sociedade Portuguesa de Gastrenterologia Publicado por S. Karger AG, Basel

\section{Introduction}

In December 2019, a new coronavirus named severe acute respiratory syndrome coronavirus 2 (SARS-CoV-2) emerged in China and was responsible for the development of Coronavirus disease 2019 (COVID-19), which was declared a pandemic in March 2020 by the World Health Organization (WHO). Until the end of March 2021, this disease had already affected around 130 million people worldwide and caused a total of 2.9 million deaths [1]. Patients with chronic diseases, such as inflammatory bowel disease (IBD), were initially considered to bear a potentially greater risk in relation to the chronic inflammation process and/or medications. While IBD patients do not seem to have a higher risk for SARS-CoV-2 infection than the general population, severe COVID-19 disease seems to be associated with some IBD medications, namely with thiopurine monotherapy or combination therapy with TNF antagonists [2].

Although significant progress has been made on the knowledge of the effects of IBD medication during the COVID-19 pandemic, patients' preferences and perspectives have not been as deeply explored [3]. Besides 
Table 1. General characteristics of the study population

\begin{tabular}{lc}
\hline Mean age \pm SD, years & $41.7 \pm 12.1$ \\
Gender, $\%(n / N)$ & \\
$\quad$ Female & $79.6(109 / 137)$ \\
$\quad$ Male & $20.4(28 / 137)$ \\
Disease type, \% $(n / N)$ & \\
$\quad$ Crohn's disease & $65.7(90 / 137)$ \\
$\quad$ Ulcerative colitis & $32.1(44 / 137)$ \\
$\quad$ Unclassified IBD & $2.2(3 / 137)$ \\
Treatment, \% $(n / N)$ & \\
$\quad 5-A S A$ & $48.9(67 / 137)$ \\
$\quad$ Oral corticosteroids in the previous three months & $21.2(29 / 137)$ \\
$\quad$ Immunomodulators (thiopurines or methotrexate) monotherapy & $18.2(25 / 137)$ \\
$\quad$ Biologic therapy & \\
$\quad$ Biologic monotherapy & $30.0(41 / 137)$ \\
$\quad$ Combination therapy (immunomodulators plus biologic) & $19.0(26 / 137)$ \\
Disease duration, years, \% ( $n / N)$ & \\
$\quad<10$ & $51.8(71 / 137)$ \\
$\quad \geq 10$ & $48.2(66 / 137)$ \\
Disease activity, \% ( $/ N)$ & \\
$\quad \begin{array}{l}\text { Active } \\
\text { Clinical remission }\end{array}$ & $50.4(69 / 137)$ \\
Previous surgery, \% $(n / N)$ & $49.6(68 / 137)$ \\
$\quad$ No & \\
Yes & $60.6(83 / 137)$ \\
\hline
\end{tabular}

acknowledging therapy-related risk concerns, many other aspects of IBD management were affected, such as medical appointments or follow-up exams. In a previous global survey, only $50 \%$ of the patients received COVID-19 information or specific recommendations from their doctors and only $11 \%$ found a relief from their fears and concerns after medical consultation [3]. Nevertheless, most patients did not want to discontinue their medication during the pandemic [3]. Still, whether IBD patients would like to discuss therapy changes to their on-going regimens remains unknown. Finally, it is known that patients with chronic diseases, such as IBD, may feel additional obstacles in their work environment, which may be exacerbated during a pandemic [4].

To improve IBD care during the COVID-19 outbreak, it is crucial not only to follow clinical practice recommendations, but also to understand patients' perspectives and fears about the management of their chronic disease and the clinical, personal, and social impact of this new pandemic. To our knowledge, no study has formally assessed patients' perspectives during the COVID-19 outbreak in Portugal.

Herein, we conducted an observational study with the support of the Portuguese Association of Inflammatory Bowel Disease (APDI) to evaluate IBD patients' perspec- tives on the clinical management of their disease during the COVID-19 pandemic and the interaction with healthcare services, but also to highlight the influence of this outbreak on their professional life.

\section{Materials and Methods}

\section{Study Design and Population}

We conducted a national web survey, where we first assessed patients' fears/concerns, potential risks, and benefits of IBD therapy and if they were considering a change in their maintenance therapy. Second, we focused on disease management, follow-up, communication with IBD specialists, and patients' proposals to improve medical care. Finally, we assessed the impact of the pandemic on professional activity.

The anonymous electronic survey was created using REDCap and was distributed by APDI between May and August 2020, using their social media and email communication with affiliates. The questionnaire was developed in Portuguese with the cooperation of IBD specialists and distributed through the National Centre for the Registry of Data in Gastroenterology (CEREGA). Only questions with closed answers were included. All patients with IBD, including Crohn's disease (CD), ulcerative colitis (UC), and unclassified IBD, were asked to participate.

\section{Data Collection}

Demographic data was collected, including disease type $(C D$, UC, or unclassified IBD), current treatment, disease activity, and previous surgeries. Disease activity was subjectively defined ac- 


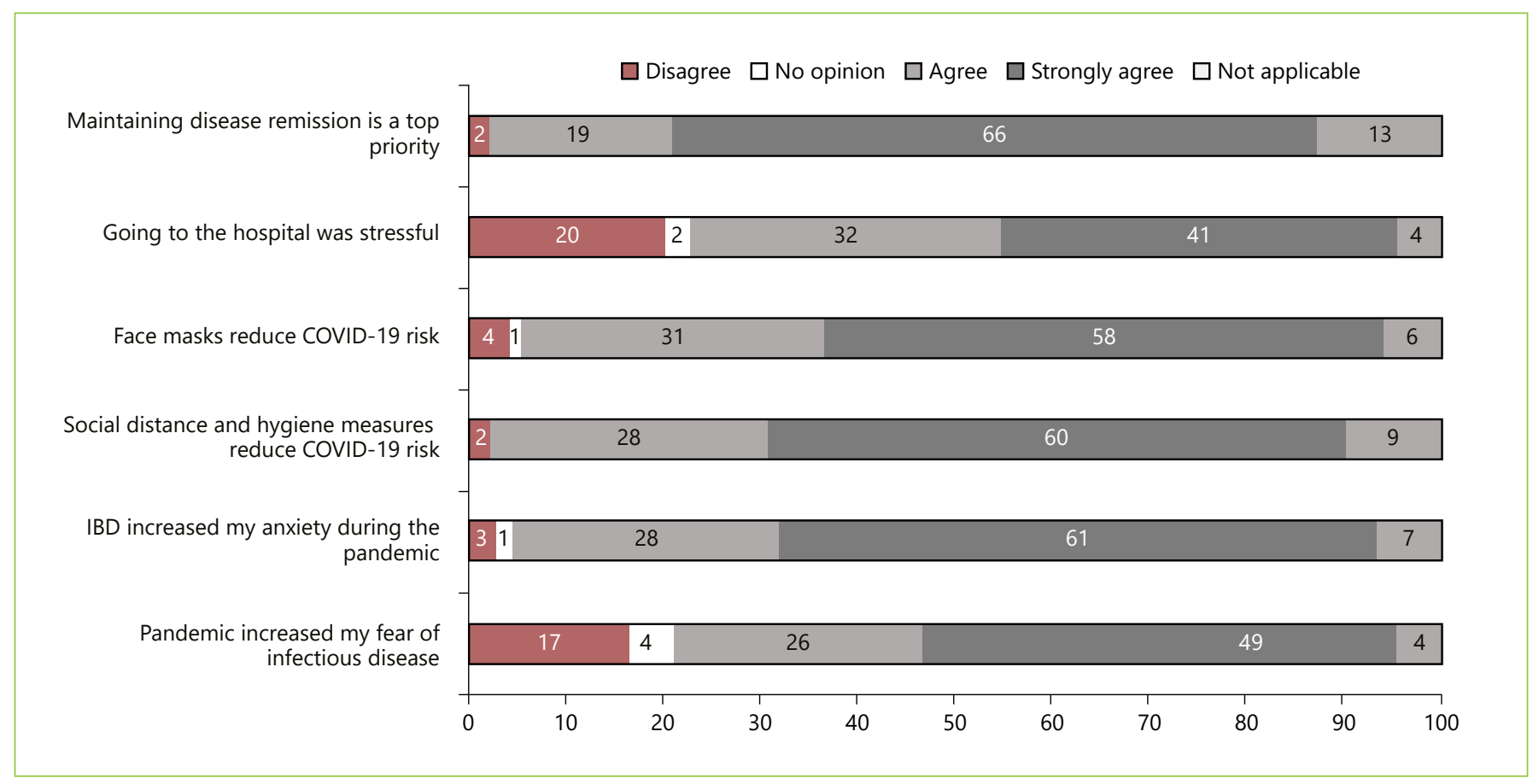

Fig. 1. Patients' perspectives on SARS-CoV-2 risk. Answers were categorized into 5 subgroups: disagree, no opinion, agree, strongly agree, or not applicable.

cording to patients' symptoms. Patients were considered to be on remission if no symptoms were present. Disease duration was characterized as $<10$ years or $>10$ years. Biologic treatment included patients on TNF antagonist monotherapy or in combination therapy with immunomodulators, as well as those treated with anti-integrin $\alpha 4 \beta 7$ or anti-interleukin 12/23. Concerning professional activity, only actively employed patients were included in the analysis.

\section{Statistical Analysis}

Descriptive analysis for baseline characteristics was performed. Continuous variables were described as mean and standard deviation (normally distributed) or median and range (nonnormally distributed), while categorical variables were expressed as frequency and proportions. Univariable and multivariable logistic regression analysis was performed. Univariable analysis included age, disease type (CD vs. UC), disease activity (active vs. remission), disease duration ( $<10$ vs. $\geq 10$ years), therapy (biologic vs. no biologic), corticosteroid use in the past 3 months (yes vs. no), and previous surgery (yes vs. no). Multivariable models included variables with a $p$ value $<0.1$ in univariate analysis and/ or variables considered to be significant for the model building. A $p$ value $<0.05$ was considered statistically significant. Statistical analysis was performed using the software Statistical Package for the Social Sciences (SPSS; version 23.0) and Stata package version 16.

(1)

\section{Results}

A total of 137 participants followed in public or private national hospitals answered the survey. Most patients had $\mathrm{CD}$, with a mean age of 41.7 years and a predominance of females (Table 1).

\section{Patients' Fears, Potential Risks, and Benefits of IBD Therapy}

Most patients stated that having IBD and being immunosuppressed lead to anxiety during the pandemic $(90.4 \%$, $n=122 / 135)$ and that going to the hospital was a promotor of stress $(73.3 \%, n=99 / 135)$. Nevertheless, $85.4 \%$ $(n=117 / 137)$ of the participants agreed or strongly agreed that keeping IBD under control was crucial (Fig. 1).

The most significant fears of patients were the risk of needing invasive mechanical ventilation $(70.8 \%, n=$ 97/137), the risk of being hospitalized $(62.8 \%, n=86 / 137)$, and the risk of dying from SARS-CoV-2 infection (53.3\%, $n=73 / 137)$. Only $20.4 \%(n=28 / 137)$ of the patients were fearful of having to interrupt their current treatment due to SARS-CoV-2 infection.

Regarding IBD therapy, $44.4 \%(n=59 / 133)$ of the patients believed that their current treatment increased the 
Table 2. Multivariate analysis of patients' perspectives on the risk of being infected by SARS-CoV-2 and the risk of severe disease

\begin{tabular}{llc}
\hline Variable & $\begin{array}{l}\text { Univariate logistic regression, } \\
\text { OR }(95 \% \text { Cl, } p \text { value })\end{array}$ & $\begin{array}{c}\text { Multivariate logistic regression, } \\
\text { aOR }(95 \% \mathrm{Cl}, p \text { value })\end{array}$ \\
\hline Patients' perspective on the risk of being infected by SARS-CoV-2 & \\
Age (years) & $0.97(0.94-1.00,0.038)$ & $0.97(0.94-1.00,0.095)$ \\
Gender & $1.33(0.58-3.07,0.5)$ & - \\
Disease duration & $1.38(0.69-2.73,0.363)$ & - \\
Previous surgery & $1.56(0.77-3.14,0.215)$ & - \\
Biologic therapy & $3.15(1.54-6.42,0.002)$ & $3.08(1.42-6.70,0.005)$ \\
Corticosteroids in the previous 3 months & $2.59(1.08-6.20,0.033)$ & $3.91(1.39-11.02,0.01)$ \\
Disease subtype (CD vs. UC) & $2.90(1.32-6.37,0.008)$ & $3.31(1.37-7.99,0.008)$ \\
Disease activity (active disease vs. remission) & $1.6(0.81-3.19,0.182)$ & $2.62(1.15-5.97,0.02)$ \\
\hline Patients' perspective on the risk for severe COVID-19 disease & \\
Age (years) & $0.95(0.92-0.99,0.009)$ & $0.95(0.91-0.99,0.023)$ \\
Gender & $1.40(0.48-4.07,0.534)$ & - \\
Disease duration & $1.83(0.79-4.22,0.157)$ & - \\
Previous surgery & $1.68(0.70-4.02,0.242)$ & - \\
Biologic therapy & $4.38(1.73-11.11,0.002)$ & $4.00(1.46-10.93,0.007)$ \\
Corticosteroids in the previous 3 months & $2.96(0.83-10.57,0.094)$ & $5.38(1.26-22.93,0.023)$ \\
Disease subtype (CD vs. UC) & $1.98(0.85-4.61,0.114)$ & - \\
Disease activity (active disease vs. remission) & $2.47(1.05-5.78,0.037)$ & $4.20(1.57-11.28,0.004)$ \\
\hline
\end{tabular}

OR, odds ratio; aOR, adjusted odds ratio; $\mathrm{Cl}$, confidence interval.

risk of being infected with SARS-CoV-2 and $77.8 \%(n=$ $105 / 135)$ believed that their treatment could increase disease severity. Most patients $(80.9 \%, n=110 / 136)$ believed to be informed about the risks and benefits of their current treatment, the most common sources of information being the APDI (34.3\%), the Internet (25.6\%), and their gastroenterologist (19.7\%). More than half of the patients (58.8\%, $n=80 / 136)$ considered that they had the opportunity to discuss the most suitable therapeutic options with their physicians.

In the subgroup of patients treated with biologics, 30 patients $(45.5 \%)$ were treated with an intravenous biologic administered at the hospital. Of those, $66.7 \%$ believed that a screening program to detect COVID-19-related symptoms or high-risk contacts had been implemented before each hospital session and $90.0 \%$ recognized that a lower number of IBD patients were admitted during their infusion session when compared to the period before the pandemic. Despite these protective measures, $56.7 \%$ of the patients assumed that they were at an increased risk of SARS-CoV-2 infection due to their hospital-based treatment. Nevertheless, when confronted with the possibility of increasing the interval between administrations or stopping/changing their biologic treatment, more than half of the patients $(60.0 \%)$ preferred not to change their treatment regimen. Patients were only willing to discuss a change in their treatment if there was no risk for relapse $(60.7 \%, n=17 / 28)$ or if the risk was low to moderate $(25 \%, n=7 / 28)$.

In the subgroup of patients treated with self-administered biologics at home $(n=37)$, only $20.6 \%$ had the opportunity to obtain the medicine from a community pharmacy during the pandemic. Nevertheless, $64.7 \%$ of the patients believed that this could help reduce the risk of SARS-CoV-2 infection and 70.6\% highlighted that it could reduce unnecessary dislocations to the hospital.

Only 6 patients $(4.4 \%)$ interrupted their treatment since the beginning of the pandemic, two of them by their own initiative. The remaining 4 patients stopped their medication according to their doctor's recommendation and they were all being treated with adalimumab.

In a multivariate analysis, treatment with biologics or corticosteroids use in the previous 3 months, CD, and active disease were perceived by patients to be high-risk features for SARS-CoV-2 infection. Age, active disease, and use of biologics or corticosteroids in the previous 3 months were also considered by patients to be predictors of severe COVID-19 disease (Table 2). 


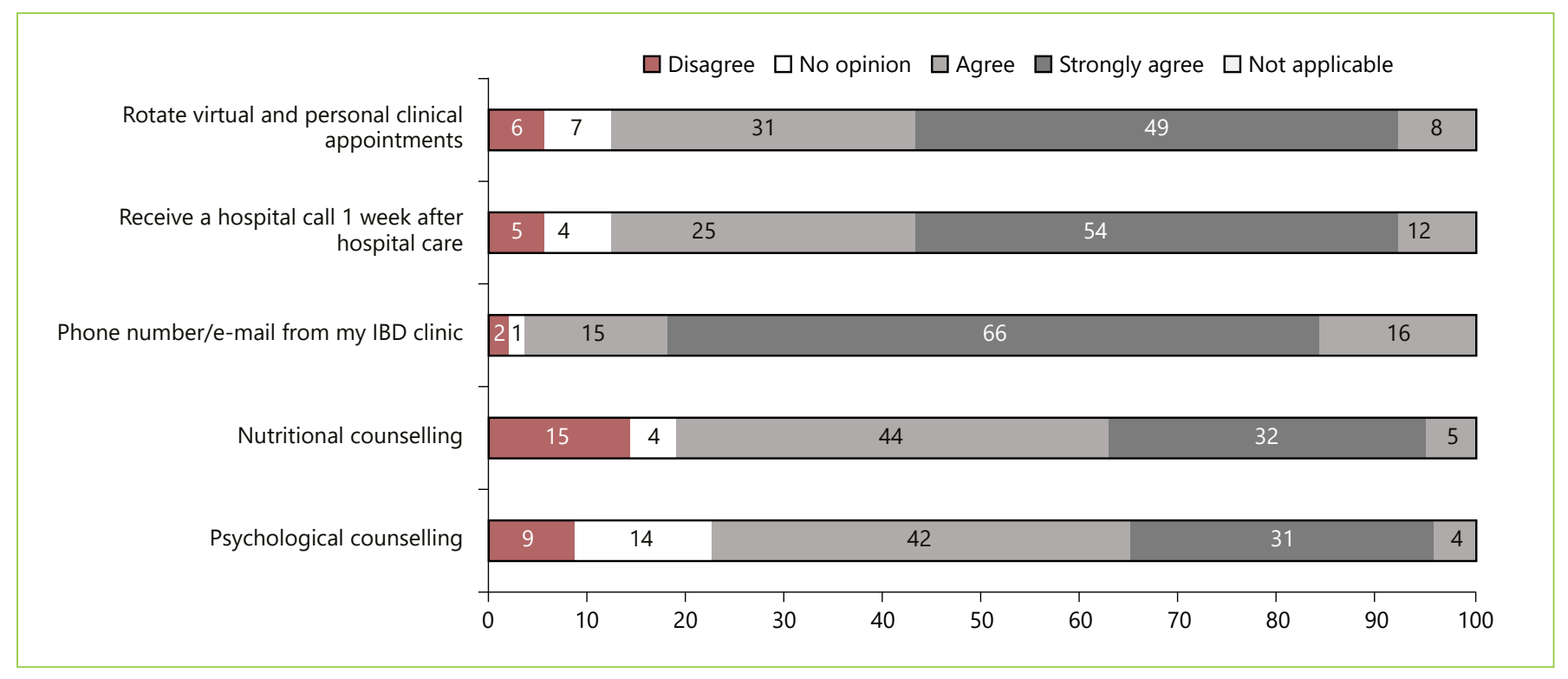

Fig. 2. Patients' proposals to improve medical care in IBD. Answers were categorized into 5 subgroups: disagree, no opinion, agree, strongly agree, or not applicable.

Patients' Perspectives on Disease Management, Follow-Up, and Gastroenterology Department

\section{Communication}

Overall, $44.0 \%$ ( $n=59 / 134)$ of the patients considered that their follow-up was influenced by the pandemic. When analyzing different aspects of the follow-up, only a minority of the patients $(7.5 \%, n=10 / 134)$ considered that virtual/phone appointments were inappropriate to guarantee an adequate follow-up; most believed that their nonurgent colonoscopy could be postponed $(87.7 \%, n=$ $114 / 130)$; and $61.3 \%$ of the patients $(n=84 / 137)$ thought that the pandemic did not change their possibilities of treatment. More than half of the patients $(65.4 \%, n=$ 89/136) believed that virtual/phone appointments could be considered a hypothesis, even after the pandemic is over.

Regarding the communication with the gastroenterology department, no significant changes were observed before and after the pandemic. The 3 most common ways of communication were the hospital's, the attending physician's, or the personal IBD nurse's phone number (online suppl.Fig. 1, seewww.karger.com/doi/10.1159/000518945). Half of the patients (50.4\%) thought that there was an effort from the gastroenterology department to improve communication and 85 patients $(64.4 \%)$ thought that there was an effort to improve patients' safety.

\section{Patients' Proposals to Improve Medical Care}

Most patients found that there was a need for enhancing the communication with the gastroenterology department, including having a more direct phone number $(80.9 \%)$ or email $(79.4 \%)$ to contact the medical and nurse team. They also considered that it would be important to be contacted by the professionals for a follow-up after biologic administration (79.0\%).

Other proposals that patients agreed or strongly agreed to implement during the pandemic were the possibility of having a learning video explaining the hygiene care to be taken out of home $(81.0 \%, n=111 / 137)$; rotate face-toface with virtual/phone appointments $(80.0 \%, n=$ $109 / 137)$; having a nutritional $(76.0 \%, n=104 / 137)$ and psychological support $(73.0 \%, n=100 / 137)$; collecting blood samples outside of the hospital setting $(71.1 \%, n=$ $96 / 135)$, and the possibility of having domiciliary administration of intravenous medications $(68.7 \%, n=92 / 134$; Fig. 2).

\section{Impact of the Pandemic on Patients' Professional} Activity

During the pandemic, 63 patients $(64.3 \%, n=63 / 98)$ were working from home. This decision was related to their disease in $36.5 \%(n=23)$ of the cases and to their immunosuppressive medication in $39.7 \%(n=25)$. Of those who continued to go to their physical workplace $(n=35)$, 
Table 3. Univariate analysis of predictive factors of the decision to be working from home in those patients whose decision was related to IBD

\begin{tabular}{lcc}
\hline Variable & Univariate adjusted OR (95\% Cl) & $p$ value \\
\hline Predictors of the decision to be working from home in those & patients whose decision was related to IBD \\
Age (years) & $0.97(0.92-1.02)$ & 0.191 \\
Sex (female vs. male) & $0.28(0.55-1.43)$ & 0.125 \\
Disease subtype (CD vs. UC) & $1.16(0.41-3.25)$ & 0.778 \\
Previous surgery & $1.42(0.51-3.92)$ & 0.504 \\
Disease activity (active disease vs. remission) & $1.20(0.44-3.31)$ & 0.719 \\
Disease duration ( $\geq 10$ vs. <10 years) & $1.41(0.51-3.90)$ & 0.503 \\
Biologic therapy & $0.875(0.31-2.47)$ & 0.801 \\
Corticosteroids in the previous 3 months & $0.46(0.08-2.51)$ & 0.372
\end{tabular}

OR, odds ratio; $\mathrm{Cl}$, confidence interval.

10 patients (28.6\%) saw their employers introducing changes to the working environment due to their disease and one $(2.9 \%)$ changed his working position because of IBD. Twenty-six patients $(26.5 \%, n=26 / 98)$ were asked by their employer if any special caution should be taken due to IBD and 9 patients $(9.2 \%, n=9 / 98)$ needed to submit a medical report of the disease. Two patients $(2.0 \%$, $n=2 / 98$ ) lost their job during the pandemic, none of them was due to IBD. Eighty-six $(87.8 \%, n=86 / 98)$ patients agreed or strongly agreed that it would be useful to explain disease- and therapy-related risks to their employers and $82.7 \%$ ( $n=81 / 98)$ believed that it would be useful to have a medical report attesting their condition, so that it could be delivered to the employer when they were not working from home. In univariate analysis, including patients whose decision to be working from home was related to IBD, neither age, sex, disease type, previous surgery, disease activity, disease duration, treatment with biologics, or use of corticosteroids in the previous 3 months influenced the decision of remote working (Table 3 ).

\section{Discussion}

In this study, we assessed patients' perspectives, fears, and preferences in IBD management during the COVID-19 pandemic in Portugal, in order to help health professionals address patients' concerns and improve patients' and doctors' cooperation in the management of IBD.

Most patients recognized that having IBD and being immunosuppressed lead to anxiety and feared the need for invasive mechanical ventilation, hospitalization, or death due to COVID-19 disease. Nevertheless, the majority $(85.4 \%)$ stated that keeping the disease under control was critical. These perspectives agree with international societies' recommendations, which suggest that therapeutic goals and strategies for IBD should not change because of the pandemic, even though the risks of disease severity due to immunosuppression should be weighed against the risk of recurrence [5-7]. Patients treated with intravenous biologics were only willing to discuss a change in their treatment if there was no risk of relapse or if the risk was considered to be low to moderate, potentially influenced by a more severe bowel disease in those patients. This is aligned with a previous study from the pre-COVID-19 era, where CD patients would not accept a risk of relapse higher than $25 \%$ when therapy de-escalation from combination therapy was discussed [8]. Moreover, only 6 patients (4.4\%) interrupted their treatment during the pandemic, 4 of them stopping adalimumab according to their doctor's indication. Even though there is no current recommendation to stop TNF antagonists during the pandemic, adalimumab withdrawal could be explained by the few available data when these decisions were made. The low rate of therapy withdrawal due to patients' initiative also highlights their compliance with therapy regimens. To date, anti-TNF therapy does not seem to increase the risk of infection. However, IBD patients treated with thiopurines in monotherapy or combination therapy with TNF antagonists seem to have a higher risk for severe COVID-19 disease, whereas those treated with TNF antagonists in monotherapy do not [2].

In our study, patients also clearly distinguished the risk of infection and the risk of severe disease. Only $44.4 \%$ of the patients believed that their current treatment could increase 
the risk of being infected with SARS-CoV-2, whilst $77.8 \%$ believed that their treatment could increase disease severity. In fact, patients treated with biologic or with corticosteroids in the previous 3 months considered themselves to be at a higher risk of infection and severe disease. Similarly, disease activity was also considered to be a high-risk feature. On the other hand, disease duration did not influence the perception of SARS-CoV-2 risk, whereas age was only associated with disease severity. Altogether, these factors suggest that IBD patients believe that therapy and disease activity are the most important factors to determine COVID-19 outcomes. Importantly, our population may not be representative of all Portuguese IBD patients, since included patients were all associated with APDI and may represent a more informed population.

Regarding hospital-based treatments, more than half of the patients assumed that a screening program and protective measures had been implemented to reduce SARS-CoV-2 transmission. Nevertheless, $56.7 \%$ still considered being at an increased risk of infection during each infusion session, probably because COVID-19 patients receive care in the same hospital setting as IBD patients, which could increase the contagion risk. Moreover, only $58.8 \%$ of the patients had the opportunity to discuss their treatment options with their doctor.

Overall, our results are aligned with a previously published survey from the European Federation of Crohn's and Ulcerative Colitis Associations (EFCCA), where 63\% of patients were afraid that medication could increase the risk of infection, but only $4 \%$ stopped medication by their own initiative. Moreover, one-third of patients would like to have more information about COVID-19 from their doctors and $75 \%$ were afraid to go to hospital/IBD center [3]. We further explored patients' recommendations and found some opportunities to improve medical care. First, no differences in communication were observed before and after the COVID-19 pandemic, offering a possibility for gastroenterology departments to work on measures to facilitate the communication with their patients, namely through the creation of a direct telephone number or email, if not existent already. Face-to-face appointments could also be rotated with virtual appointments, as agreed by $79.6 \%$ of the patients. It is worth mentioning that although telemedicine was not routinely used in Portugal, Portuguese hospitals showed a great capacity to adapt to COVID-19 restrictions, substantially increasing the number of virtual appointments. In fact, telemedicine in IBD had already been developed in the pre-pandemic area, including not only virtual appointments, but also the distribution of medical surveys to trace disease flares or even the use of platforms to provide high-quality care, improve treatment adherence, and identify disease progression at early stages, such as myIBDcoach or HealthPROMISE [9-11]. Moreover, telemedicine has already been explored as a diagnostic tool, with home-based fecal calprotectin measurements showing a strong correlation with laboratory analysis [12]. Altogether, and considering all the uncertainties on how the current pandemic will evolve and being aware that IBD affects a young and very active population, telemedicine is probably going to be part of IBD standard of care and measures for its implementation should be developed [13]. Finally, a minority of the patients had the opportunity to obtain self-administered biologics from a community pharmacy. During a pandemic and in an era of growing interest in telemedicine, availability of these treatments in community pharmacies should also be improved.

In terms of the impact of the pandemic on professional activity, $64.3 \%$ of the patients were working from home. Although in approximately one-third of the cases this decision seemed to be related with the disease or immunosuppressive therapy, it is important to highlight that during the period where the questionnaire was implemented, Portugal was recovering from lockdown and, therefore, most people were encouraged to work from home. In fact, no IBD-related factor, such as age, disease type, disease activity, previous surgery, and treatment with biologics or corticosteroids, influenced the decision to be working from home. Even though patients do not have to tell their employer of their IBD condition due to medical confidentiality, more than half of the patients agreed that it would be useful if their employers were informed about the risks of their disease and immunosuppressive therapy.

To our knowledge, this was the first study to formally assess patients' perspectives in terms of therapeutic management, disease follow-up, patients' proposals, and professional activity during the COVID-19 pandemic in Portugal. Being focused on patients' perspectives on IBD management, this study offers some reflections and proposals that could transit to the period after the pandemic to increase patients' satisfaction and compliance with healthcare recommendations. Our study also has some limitations, namely the fact that the questionnaire was long and, therefore, some patients did not fully complete all the answers, which created some heterogeneity in our sample size between questions. Nevertheless, in each question, we only had a variation of 1-5 answers, and we do not think this would have changed our results. Finally, this survey was only available after the first wave of COVID-19 and needs to be further extended. 
In summary, most patients considered that maintaining disease remission during the COVID-19 pandemic was crucial, which is in line with international IBD recommendations. Active disease, biologic treatment, and use of corticosteroids in the last 3 months were perceived by the patients as high-risk features, leading to increased risk of infection and severe disease. Even though patients recognized the efforts of gastroenterology departments to improve medical care during therapeutic sessions, communication before and after the COVID-19 pandemic did not change. In fact, patients proposed to create direct channels for communication, either with a doctor or IBD nurse, and to maintain virtual appointments. Finally, IBD did not seem to have influenced professional activity during this period and most professional decisions were related to the pandemic itself.

\section{Statement of Ethics}

This research was conducted ethically in accordance with the World Medical Association Declaration of Helsinki. All patients provided oral and written informed consent to participate in the study.

\section{Conflict of Interest Statement}

J.T. received speaker and consulting fees from Janssen and consulting fees from Arena Pharmaceuticals, and Gilead and Galapagos.

\section{Funding Sources}

The RedCap eCRF development was supported by the Portuguese Society of Gastroenterology, through its platform for multicenter studies, CEREGA.

\section{Author Contributions}

J.B.R., C.F.-G., and J.T. contributed to the manuscript concept and design. C.F.-G., B.M., C.N., C.P., C.F., L.R.R., A.S., L.G., M.C., and J.T. contributed to the development and distribution of the questionnaire. J.B.R. and C.F.-G. performed the statistical analysis. J.B.R., C.F.-G., and J.T. wrote the manuscript. All authors critically revised the manuscript. All authors have approved the final version of the manuscript.

\section{References}

1 Worldmeter. 2021 [cited Jan 31, 2021]. Available from: https://www.worldometers.info/ coronavirus/.

2 Ungaro RC, Brenner EJ, Gearry RB, Kaplan GG, Kissous-Hunt M, Lewis JD, et al. Effect of IBD medications on COVID-19 outcomes: results from an international registry. Gut. 2021 Apr;70(4):725-32.

3 D'Amico F, Rahier JF, Leone S, Peyrin-Biroulet L, Danese S. Views of patients with inflammatory bowel disease on the COVID-19 pandemic: a global survey. Lancet Gastroenterol Hepatol. 2020 Jul;5(7):631-2.

4 Le Berre C, Peyrin-Biroulet L, Buisson A, Olympie A, Ravel MH, Bienenfeld C, et al. Impact of inflammatory bowel diseases on working life: A French nationwide survey. Dig Liver Dis. 2019 Jul;51(7):961-6.

5 Magro F, Rahier JF, Abreu C, MacMahon E, Hart A, van der Woude CJ, et al. Inflammatory Bowel Disease Management During the COVID-19 Outbreak: The Ten Do's and
Don'ts from the ECCO-COVID Taskforce. J Crohn's Colitis. 2020 Oct;14(14 Suppl 3): S798-806.

6 GEDII. DII na era COVID-19: o que muda na abordagem clínica à organização dos centros - a realidade Portuguesa. 2020.

7 Rubin DT, Abreu MT, Rai V, Siegel CA, Ahuja V, Allez M, et al.; International Organization for the Study of Inflammatory Bowel Disease. Management of Patients with Crohn's Disease and Ulcerative Colitis During the Coronavirus Disease-2019 Pandemic: Results of an International Meeting. Gastroenterology. 2020 Jul;159(1):6-13.e6.

8 Siegel CA, Thompson KD, Walls D, Gollins J, Buisson A, Olympie A, et al.; BIOCYCLE group. Perspectives From Patients and Gastroenterologists on De-escalating Therapy for Crohn's Disease. Clin Gastroenterol Hepatol. $2021 \mathrm{Feb} ; 19(2): 403-5$.

9 Perisetti A, Goyal H. Successful Distancing: Telemedicine in Gastroenterology and Hepa- tology During the COVID-19 Pandemic. Dig Dis Sci. 2021 Apr;66(4):945-53.

10 IBDcoach. 10/05/2021. Available from: https://ibd.coach/.

11 HealthPROMISE. 10/05/2021. Available from: https://rx.health/healthpromise/.

12 Heida A, Knol M, Kobold AM, Bootsman J, Dijkstra G, van Rheenen PF; Agreement Between Home-Based Measurement of Stool Calprotectin and ELISA Results for Monitoring Inflammatory Bowel Disease Activity. Agreement Between Home-Based Measurement of Stool Calprotectin and ELISA Results for Monitoring Inflammatory Bowel Disease Activity. Clin Gastroenterol Hepatol. 2017 Nov;15(11):1742-9.e2.

13 Lewin S, Lees C, Regueiro M, Hart A, Mahadevan U. International Organization for the Study of Inflammatory Bowel Disease: Global Strategies for Telemedicine and Inflammatory Bowel Diseases. J Crohn's Colitis. 2020 Oct;14(14 Suppl 3):S780-4. 